\title{
"I know I have arthritis but I don't know what type". Understanding and knowledge of this chronic condition
}

\author{
Tiffany K Gill ${ }^{1,2^{*}}$, Catherine L Hill ${ }^{3 \dagger}$, Robert J Adams ${ }^{4 \dagger}$, Danny Broderick ${ }^{5 \dagger}$, Julie Black ${ }^{6 \dagger}$, Anne W Taylor ${ }^{1,2+}$
}

\begin{abstract}
Background: "Arthritis" is a common musculoskeletal condition but the knowledge of what type of arthritis people have, may be limited but may have changed over time in response to campaigns, increased awareness and improved health literacy. This paper describes people who did not know what type of arthritis they had, by a range of relevant demographic and socioeconomic variables, and assesses changes over time in the proportion of people who report having arthritis but do not know what type, using representative population surveillance data.

Methods: Data were collected using the South Australian Monitoring and Surveillance System (SAMSS), a risk factor surveillance system where each month, a representative random sample of South Australians is selected from the Electronic White Pages, with interviews conducted using computer assisted telephone interviewing (CATI). Data were used for the period January 2006 to December $2008(n=16465)$ for respondents aged 18 years and over.
\end{abstract}

Results: Overall, the proportion of respondents who did not know what type of arthritis they had, among people aged 18 years and over, for 2006 to 2008 was 6.5\% (95\% Cl 6.1-6.9). When considering only those respondents reporting that they had been told by a doctor that they had arthritis, 30.1\% did not know what type of arthritis they had. Multivariate analysis indicated that males, those with have a trade, certificate or diploma or secondary level of education, who spoke a language other than English at home, were widowed and earned $\$ 20,001$ to $\$ 60,000$, more than $\$ 80,000$ or did not state their income were more likely to maintain that they did not know what type of arthritis they had.

Conclusions: Population ageing and an increase in arthritis prevalence in the future will further increase the burden of arthritis. These increases in prevalence are not inevitable, especially if investments are made in public health prevention programs, particularly those addressing cultural and linguistic diversity and differences in socioeconomic status and health literacy.

\section{Background}

Chronic disease is a crucial public health issue [1]. Being able to provide policy and planning experts with quality data to assist them in their decision making is important, in an endeavour to provide appropriate preventive and management policies, programs and interventions. In our ageing society, where scarce health resources are being spread increasingly thin, evidence-based, valid,

\footnotetext{
* Correspondence: tiffany.gill@health.sa.gov.au

+ Contributed equally

'Population Research \& Outcomes Studies Unit, SA Health, Adelaide, SA, Australia

Full list of author information is available at the end of the article
}

population-wide estimates of chronic conditions are required by decision-makers. The self-report nature of many of the data elements collected using population surveys rely on people understanding their condition. One area of concern is when patients do not understand what has been told to them - even, in some instances, the most basic labelling of the condition they have been diagnosed with. Arthritis is one example of a chronic condition where self-report estimates may be compromised because of the lack of comprehension or understanding associated with the diagnosis.

Health literacy is described as having the ability to perform basic reading and numerical tasks required to 
function in a health care environment [2]. Health literacy is vital to all people, but people with chronic diseases in particular, to ensure reasonable measures are taken for treatment and maintenance of the condition. Having poor or inadequate health literacy can contribute to a variety of outcomes including: poor compliance, uncontrolled chronic disease, difficulties with accessing health care, following instructions from a physician or taking medication properly, and inability to complete forms [2]. All of these activities are compromised when people do not even know exactly what condition they are dealing with.

Not only has it been shown that there is a significant association between less knowledge of one's illness and lower functional health literacy levels (FHL) [3], it has been documented that patients with inadequate health literacy also have difficulty controlling chronic illnesses [3-5]. Health promotion programs and disease prevention initiatives are less likely to reach those with poor health literacy [5] and lower literacy skills correlate with poorer self-reported health status [6]. Age, education and income level are associated with low health literacy [7] and reading ability is also an indicator of functional literacy skills [8]. In assessing health literacy, it has been shown that the highest level of education completed is often higher than the actual level of literacy [9].

People with less health literacy are less likely to ask questions of clinicians. One of the assumptions of the chronic care model is that the reorganization of health care will lead to more productive interactions with informed, involved patients, leading to better outcomes. Yet policies promoting more choice may run the risk of creating a two-tiered system in terms of access, where health literate individuals are able to exercise greater choice, whilst vulnerable groups, such as the elderly, disabled, less educated, or socially excluded, 'fall through the net'. A lack of clarity around a person's diagnosis and condition makes self-management very problematic.

Arthritis is recognised as a major burden on public health across the western world [10], although diseases with more acute mortality often receive more attention [11]. Arthritis is a highly prevalent condition, particularly for women and those in older age groups [10-14]. As of 2008, it is estimated that arthritis affected approximately three million Australians, $16.5 \%$ of the total population [15]. This number has been estimated to be higher in South Australia (SA), with approximately a fifth of the SA population reporting that they have arthritis [16]. In recognition of the health and economic burden arthritic conditions cause, and because of the potential for health gain through prevention and lessening of the impact of the diseases, the Australian Federal Government established arthritis and musculoskeletal conditions as a National Health Priority Area in 2002 [15].
Surveillance data describing chronic conditions is critical for increased recognition of the public health burden of these conditions, formulating health care policy, identifying high-risk groups, developing strategies to reduce the burden, and evaluating progress in disease prevention and control [17]. Effective surveillance of chronic disease prevalence and projections of the number of people expected to have chronic conditions in the future provides important information for the allocation of resources to prevention and health service planning. Surveillance systems such as the SA Monitoring and Surveillance System (SAMSS) $[18,19]$ which has been in place since July 2002, have been instrumental in the surveillance of chronic diseases and associated risk factors in SA. Monitoring chronic conditions is important in SA as this state has an ageing population, with the highest proportion of people aged 85 years and over and the lowest proportion aged 0 to 14 years in Australia in 2007, and a total fertility rate of 1.79 in 2006 [20]. Overall, approximately $73 \%$ of the SA population live in the capital city, Adelaide [20], and approximately $26 \%$ were born overseas [21].

The aims of this paper are to describe the proportion of people in SA, aged 18 years and over, who acknowledge that they have arthritis, but do not know what type, and to describe the demographic and socioeconomic characteristics of these respondents so that appropriate targeting strategies can be put in place. In addition, changes over time in the proportion of people who report having arthritis but do not know what type, will be assessed.

\section{Methods}

SAMSS is a health surveillance system of randomly selected participants that has been conducted monthly since July 2002 and monitors key indicators for national and state priority health and related issues among South Australians of all ages. SAMSS ensures that appropriate, timely and valid population health information is available to monitor health status, respond to changing population health needs, and support planning, implementation, and evaluation of health services and programs. All households in SA, with a number listed in the Electronic White Pages (EWP) were eligible for selection in the sample. A letter introducing SAMSS and informing people of the purpose of the survey is sent to the household of each selected telephone number. Within each household, the person who had their birthday last is selected for interview (surrogate interviews conducted for those 15 years or under). Approximately 600 interviews per month are conducted in English. Overall, the response rate for SAMSS from June 2002 until December 2008 has been approximately $60-70 \%$ each month. 
The Computer Assisted Telephone Interview (CATI) system is used to conduct the interviews. At least ten call backs are made to the telephone number selected to interview household members. Replacement interviews for persons who could not be contacted or interviewed are not permitted. Weighting is used to correct for disproportionality of the sample with respect to the population of interest. The data are weighted by age, sex and area of residence to the latest Census or Estimated Residential Population (ERP), to reflect the structure of the population in SA. Probability of selection in the household is calculated based on the number of people in the household and the number of telephone listings in the White Pages.

Respondents to each survey are asked a range of health-related questions. Arthritis prevalence was determined by asking the following question and multiple responses were possible:

Have you ever been told by a doctor that you have arthritis? (If yes, what type?)

- Yes, Osteoarthritis

- Yes, Rheumatoid Arthritis

- Yes, Juvenile Rheumatoid Arthritis (JRA)

- Yes, other (specify)

- No, don't have arthritis

- Yes, don't know type

Socioeconomic status is assessed using the Socioeconomic Index for Areas (SEIFA) Index of Relative Social Disadvantage (IRSD). These values are produced by the Australian Bureau of Statistics to measure socioeconomic status by postcode. IRSD scores have been grouped into quintiles (highest, high, middle, low and lowest) for analysis, where the highest quintile represents postcodes with the highest IRSD scores (most advantaged areas) and the lowest quintile represents postcodes with the lowest IRSD scores (most disadvantaged areas) [22]. Other demographic characteristics of respondents such as age, sex, country of birth, income level and education are also determined and since 2007 respondents have been asked their age when arthritis was diagnosed. Data presented in this paper were analysed using Chi-square tests, t-tests, univariate and multivariate logistic regression using SPSS for Windows Version 15.0 [23]. Variables that were significant at p < 0.25 were included in the initial multivariate analysis [24] with the final model comprising variables that were significant at $\mathrm{p}<0.05$.

\section{Results}

Overall, of all respondents aged 18 years and over in SA between January 2006 to December 2008, 21.6\% (95\% CI 20.9-22.2) stated that they had one or more forms of doctor diagnosed arthritis. Multiple responses were possible. The proportion of respondents self-reporting that they had osteoarthritis (OA) was 11.7\% (95\% CI 11.2-12.2), rheumatoid arthritis (RA) $2.8 \%$ (95\% CI 2.63.1), JRA $0.1 \%$ (95\% CI 0.06-0.2) and other types of arthritis $0.9 \%$ (95\% CI 0.8-1.1). Overall, the proportion stating that they did not know what type of arthritis they had, was $6.5 \%$ (95\% CI 6.1-6.9). This equates to approximately 80,000 South Australians [21]. When considering only the respondents reporting that they had been told that they had arthritis, 30.1\% (95\% CI 28.6-31.6) did not know what type of arthritis they had. For those with arthritis, the mean age of those reporting that they did not know the type of arthritis was 61.47 years (SD 15.58) and for those who knew their type of arthritis was 62.03 (SD 14.73). There was no significant difference between the groups $(t=-0.99, p=0.32)$. Information on age when first diagnosed has also been collected since 2007. The mean age of first diagnosis for those who did not know the type of arthritis they had was 49.69 (SD 16.92) and for those who knew the type of arthritis they had, 49.21 (SD 15.98). Again there was no significant difference between the two groups $(t=$ $0.63, \mathrm{p}=0.53$ )

The overall trend in the prevalence arthritis since July 2002 is shown in Figure 1. Generally the prevalence of arthritis has remained relatively constant over time. The proportion of respondents reporting an unknown type of arthritis is shown in Figure 2. There has been a slight decline over time.

The characteristics of those unable to name the type of arthritis they had, those who knew the type of arthritis they had and also those without arthritis are presented in Table 1. Those who did not know the type of arthritis were statistically significantly more likely to: be born in a country other than Australia, speak a language other than English, be separated/divorced or widowed, have a gross household income of $\$ 40,000$ or less per year, be economically inactive (home duties, retired, student, unable to work), be in the lowest two IRSD quintiles or have secondary school as their highest level of educational attainment. In addition, the proportion of respondents who did not know the type of arthritis they have was statistically significantly higher in those aged 60 years or over $\left(\chi^{2}\right.$ test, $\left.\mathrm{p}<0.05\right)$ (Table 1 ).

Univariate odds ratios were then determined which compared the demographic characteristics of those who did not know the type of arthritis compared to those that did (Table 2). Those who did not know the type of arthritis that they had were more likely to be male, have a trade, certificate or diploma or secondary level of education, earn $\$ 20,001$ to $\$ 40,000$ or not state their income or be in the low or high SEIFA IRSD quintiles. Multivariate analysis indicated that males, those with have a trade, certificate or diploma or secondary level of education, who spoke a language other than English at 


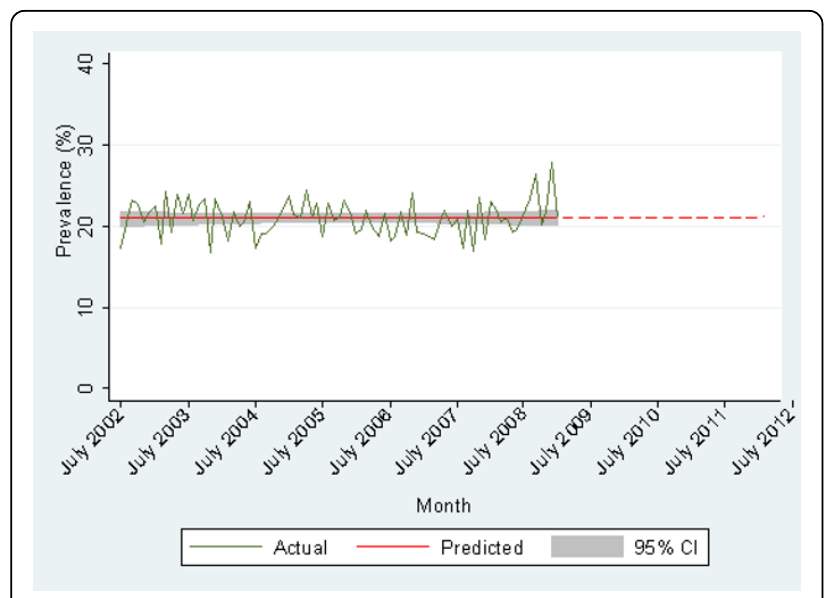

Figure 1 Prevalence of arthritis over time projected to 2012.

home, were widowed and earned $\$ 20,001$ to $\$ 60,000$, more than $\$ 80,000$ or did not state their income were more likely to state that they did not know what type of arthritis they had (Table 3).

\section{Discussion}

Population ageing continues and with it, an expected increase in arthritis prevalence in the future. This will result in a substantial increase in the number of Australians with arthritis over the next decade. While the selfreported prevalence of arthritis using telephone and questionnaire has been shown to have high agreement, the agreement is not as high when compared to clinical assessment $[11,25]$. These data have shown that there are a substantial number of adults with arthritis in the community who for a variety of reasons, do not understand the condition that they have. Previous data have also suggested that not only do respondents not know what type of arthritis they have, there is also poor

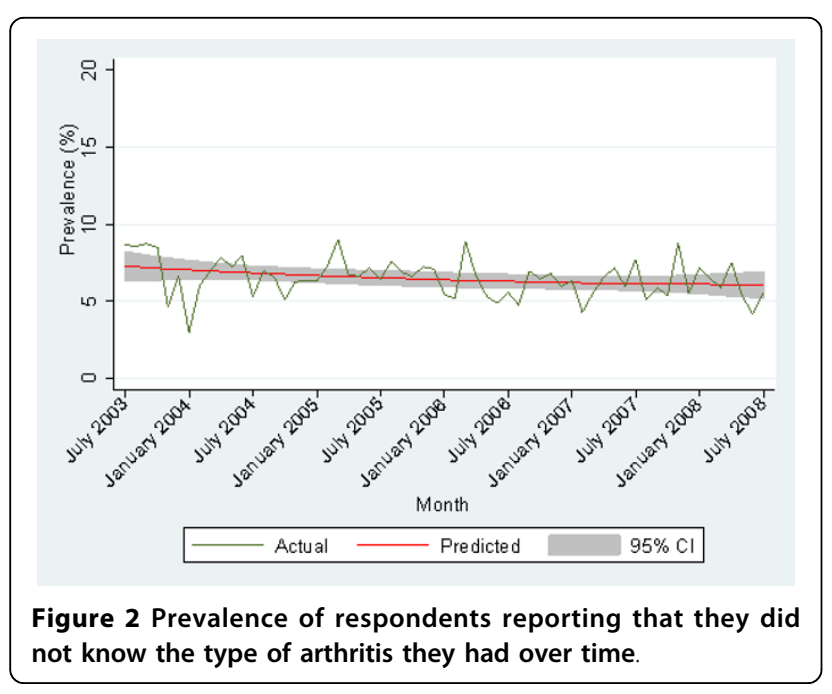

validation of self-report for specific forms of arthritis, for example people report that they have RA, however when matched with medication records this is not the case [25]. This has ramifications for prevention messages, management and treatment regimes.

It is important to be able to accurately define the types of arthritis in the community, as the health service requirements of different subtypes are quite different, thus providing policy and program implications. For example, inflammatory arthritis (such as RA, ankylosing spondylitis, psoriatic arthritis, juvenile idiopathic arthritis/JRA) requires early referral to speciality rheumatology clinics and early intervention with disease modifying agents to minimise the burden of pain and disability. In contrast, treatment of degenerative arthritis (such as $\mathrm{OA}$ ) requires multidisciplinary interventions including weight loss where appropriate, physiotherapy, education (including self-management courses) and, only in endstage disease, orthopaedic surgical referral for joint replacement surgery [15]. By addressing causes and risk factors for arthritis, promoting healthier lifestyle choices and raising disease awareness in the general population [15] those with lower FHL may be better able to reduce arthritis risk and access appropriate interventions.

The prevalence of arthritis has remained relatively stable in SA and if all factors (for example, average age and life expectancy) are maintained at current levels, it is expected that the prevalence will remain unchanged (Figure 1). However, if the population continues to age and live longer, prevalence is then likely to rise, with similar trends being reported globally. For example, using 2003-2005 data, in the United States, it was estimated that $21.6 \%$ (or 46.4 million people) of the population aged 18 years and over had arthritis (which compares with the overall prevalence of arthritis of $21.6 \%$ obtained in this study) and this was estimated to increase to approximately 67 million people (an increase of $40 \%$ ) by the year 2030 [14]. In England and Wales, between 1.3 and 1.75 million people are affected by OA and between 0.25 and 0.5 million people have RA [13]. The prevalence of arthritis in the Netherlands is $17.6 \%$ of the population aged 25 years or older [10]. In terms of Australian results, the self-reported prevalence of RA, $\mathrm{OA}$ and arthritis overall in SA are higher than national figures, however the ageing population profile in SA may account in part for this and also, particularly with regard to RA, the figure may be an overestimate due to confusion between rheumatism and RA [15].

This study shows that $30.1 \%$ of respondents with doctor diagnosed arthritis did not know what type of arthritis they had. This could be as a result of a variety of reasons including differences in definitions of arthritis. The description and meaning of different musculoskeletal diseases will differ between medical specialists, 
Table 1 Univariate analysis of demographic variables for people with and without arthritis, aged 18 years and over in South Australia, 2006-8

\begin{tabular}{|c|c|c|c|c|c|c|c|c|c|}
\hline & \multicolumn{3}{|c|}{ Arthritis - Don't know type } & \multicolumn{3}{|c|}{ Arthritis - know type } & \multicolumn{3}{|c|}{ No arthritis } \\
\hline & $\mathrm{n}$ & $\%$ & $95 \% \mathrm{Cl}$ & $\mathrm{n}$ & $\%$ & $95 \% \mathrm{Cl}$ & $\mathrm{n}$ & $\%$ & $95 \% \mathrm{Cl}$ \\
\hline \multicolumn{10}{|l|}{ Sex } \\
\hline Male & 501 & 6.2 & $(5.7-6.8)$ & 909 & $11.3 \downarrow$ & $(10.6-12.0)$ & 6651 & $82.5 \uparrow$ & $(81.7-83.3)$ \\
\hline Female & 566 & 6.7 & $(6.2-7.3)$ & 1574 & $18.7 \uparrow$ & $(17.9-19.6)$ & 6264 & $74.5 \downarrow$ & $(73.6-75.5)$ \\
\hline \multicolumn{10}{|l|}{ Age } \\
\hline 18 to 39 years & 90 & $1.5 \downarrow$ & $(1.2-1.8)$ & 181 & $3.0 \downarrow$ & $(2.6-3.5)$ & 5746 & $95.5 \uparrow$ & $(94.9-96.0)$ \\
\hline 40 to 59 years & 371 & 6.1 & $(5.5-6.7)$ & 871 & $14.3 \downarrow$ & $(13.5-15.2)$ & 4838 & $79.6 \uparrow$ & $(78.5-80.6)$ \\
\hline 60 to 79 years & 463 & $13.3 \uparrow$ & $(12.2-14.5)$ & 1122 & $32.2 \uparrow$ & $(30.7-33.8)$ & 1897 & $54.5 \downarrow$ & $(52.8-56.1)$ \\
\hline 80 years and over & 144 & $16.2 \uparrow$ & $(14.0-18.8)$ & 309 & $34.8 \uparrow$ & $(31.7-38.0)$ & 435 & $49.0 \downarrow$ & $(45.7-52.3)$ \\
\hline \multicolumn{10}{|l|}{ Country of birth* } \\
\hline Australia & 783 & $6.0 \downarrow$ & $(5.6-6.4)$ & 1828 & $14.1 \downarrow$ & $(13.5-14.7)$ & 10376 & $79.9 \uparrow$ & $(79.2-80.6)$ \\
\hline UK/reland & 138 & $8.6 \uparrow$ & $(7.3-10.1)$ & 367 & $22.8 \uparrow$ & $(20.8-24.9)$ & 1103 & $68.6 \downarrow$ & $(66.3-70.8)$ \\
\hline Other & 142 & $7.7 \uparrow$ & $(6.5-9.0)$ & 284 & 15.4 & $(13.8-17.1)$ & 1425 & 77.0 & $(75.0-78.8)$ \\
\hline \multicolumn{10}{|c|}{ Language spoken at home* } \\
\hline English & 933 & $6.3 \downarrow$ & $(5.9-6.7)$ & 2227 & 15.0 & $(14.4-15.6)$ & 11687 & $78.7 \uparrow$ & $(78.0-79.4)$ \\
\hline Other & 130 & $8.1 \uparrow$ & $(6.9-9.6)$ & 252 & 15.7 & $(14.0-17.6)$ & 1216 & $76.1 \downarrow$ & $(74.0-78.2)$ \\
\hline \multicolumn{10}{|l|}{ Marital status* } \\
\hline Married/live with partner & 728 & 6.5 & $(6.1-7.0)$ & 1731 & $15.5 \uparrow$ & $(14.9-16.2)$ & 8694 & $78.0 \downarrow$ & $(77.2-78.7)$ \\
\hline Separated/Divorced & 93 & $8.1 \uparrow$ & $(6.7-9.9)$ & 243 & $21.4 \uparrow$ & $(19.1-23.9)$ & 800 & $70.4 \downarrow$ & $(67.7-73.0)$ \\
\hline Widowed & 172 & $16.7 \uparrow$ & $(14.6-19.1)$ & 369 & $36.0 \uparrow$ & $(33.1-38.9)$ & 486 & $47.3 \downarrow$ & $(44.3-50.4)$ \\
\hline Never married & 72 & $2.3 \downarrow$ & $(1.8-2.9)$ & 138 & $4.4 \downarrow$ & $(3.7-5.2)$ & 2928 & $93.3 \uparrow$ & $(92.4-94.1)$ \\
\hline \multicolumn{10}{|l|}{ Area of residence } \\
\hline Metropolitan & 758 & 6.3 & $(5.9-6.8)$ & 1774 & 14.8 & $(14.1-15.4)$ & 9483 & $78.9 \uparrow$ & $(78.2-79.6)$ \\
\hline Country & 310 & 7.0 & $(6.2-7.7)$ & 708 & 15.9 & $(14.9-17.0)$ & 3432 & $77.1 \downarrow$ & $(75.9-78.3)$ \\
\hline \multicolumn{10}{|l|}{ Education* } \\
\hline Secondary level & 690 & $8.1 \uparrow$ & $(7.5-8.7)$ & 1533 & $18.0 \uparrow$ & $(17.2-18.8)$ & 6303 & $73.9 \downarrow$ & $(73.0-74.8)$ \\
\hline Trade/Certificate/Diploma & 267 & 6.3 & $(5.6-7.0)$ & 566 & $13.3 \downarrow$ & $(12.3-14.3)$ & 3429 & $80.5 \uparrow$ & $(79.2-81.6)$ \\
\hline Degree or higher & 108 & $3.0 \downarrow$ & $(2.5-3.6)$ & 380 & $10.4 \downarrow$ & $(9.5-11.5)$ & 3157 & $86.6 \uparrow$ & $(85.5-87.7)$ \\
\hline \multicolumn{10}{|l|}{ Work status* } \\
\hline Full time employed & 256 & $3.6 \downarrow$ & $(3.2-4.0)$ & 557 & $7.8 \downarrow$ & $(7.2-8.5)$ & 6320 & $88.6 \uparrow$ & $(87.8-89.3)$ \\
\hline Part time & 148 & $4.9 \downarrow$ & $(4.2-5.7)$ & 347 & $11.4 \downarrow$ & $(10.3-12.6)$ & 2543 & $83.7 \uparrow$ & (82.4-85.0) \\
\hline Unemployed & 19 & 4.7 & $(3.1-7.3)$ & 34 & $8.3 \downarrow$ & $(6.0-11.4)$ & 354 & $86.9 \uparrow$ & $(83.3-89.9)$ \\
\hline Economically inactive & 644 & $10.9 \uparrow$ & $(10.2-11.8)$ & 1544 & $26.2 \uparrow$ & $(25.1-27.4)$ & 3698 & $62.8 \downarrow$ & $(61.6-64.1)$ \\
\hline \multicolumn{10}{|l|}{ Income } \\
\hline Up to $\$ 20,000$ & 230 & $11.9 \uparrow$ & $(10.6-13.5)$ & 641 & $33.3 \uparrow$ & $(31.2-35.4)$ & 1053 & $54.7 \downarrow$ & $(52.5-57.0)$ \\
\hline$\$ 20,001$ to $\$ 40,000$ & 296 & $11.1 \uparrow$ & $(9.9-12.3)$ & 624 & $23.3 \uparrow$ & $(21.7-24.9)$ & 1761 & $65.7 \downarrow$ & $(63.8-67.4)$ \\
\hline$\$ 40,001$ to $\$ 60,000$ & 126 & $5.5 \downarrow$ & $(4.7-6.6)$ & 284 & $12.5 \downarrow$ & $(11.2-13.9)$ & 1866 & $82.0 \uparrow$ & $(80.4-83.5)$ \\
\hline$\$ 60,000$ to $\$ 80,000$ & 96 & $4.2 \downarrow$ & $(3.4-5.1)$ & 232 & $10.1 \downarrow$ & $(8.9-11.4)$ & 1969 & $85.7 \uparrow$ & $(84.3-87.1)$ \\
\hline$\$ 80,001$ or more & 155 & $3.3 \downarrow$ & $(2.8-3.9)$ & 378 & $8.1 \downarrow$ & $(7.4-8.9)$ & 4127 & $88.6 \uparrow$ & $(87.6-89.4)$ \\
\hline Not stated & 165 & 6.3 & $(5.4-7.3)$ & 323 & $12.3 \downarrow$ & $(11.1-13.6)$ & 2140 & $81.4 \uparrow$ & (79.9-82.9) \\
\hline \multicolumn{10}{|l|}{ SEIFA* } \\
\hline Lowest quintile & 191 & $7.5 \uparrow$ & $(6.5-8.6)$ & 429 & $16.8 \uparrow$ & $(15.4-18.3)$ & 1928 & $75.7 \downarrow$ & $(74.0-77.3)$ \\
\hline Low quintile & 241 & $7.4 \uparrow$ & $(6.5-8.3)$ & 511 & 15.7 & $(14.5-17.0)$ & 2504 & $76.9 \downarrow$ & $(75.4-78.3)$ \\
\hline Middle quintile & 226 & 6.6 & $(5.9-7.5)$ & 574 & $16.9 \uparrow$ & $(15.7-18.2)$ & 2598 & $76.5 \downarrow$ & $(75.0-77.9)$ \\
\hline High quintile & 221 & 6.5 & $(5.7-7.3)$ & 464 & $13.5 \downarrow$ & $(12.4-14.7)$ & 2741 & $80.0 \uparrow$ & (78.6-81.3) \\
\hline Highest quintile & 187 & $4.9 \downarrow$ & $(4.3-5.7)$ & 501 & $13.2 \downarrow$ & $(12.2-14.3)$ & 3103 & $81.9 \uparrow$ & $(80.6-83.1)$ \\
\hline Overall & 1068 & 6.5 & $(6.1-6.9)$ & 2482 & 15.1 & $(14.5-15.6)$ & 12915 & 78.4 & $(77.8-79.1)$ \\
\hline
\end{tabular}

Note: The weighting of the data can result in rounding discrepancies or totals not adding

*Not stated category not reported

$\downarrow \uparrow$ Statistically significantly higher or lower $\left(\chi^{2}\right.$ test, $\left.p<0.05\right)$ compared to other categories combined 
Table 2 Univariate analysis of demographic variables for adults with arthritis but don't know type, South Australia, 2006-8

\begin{tabular}{|c|c|c|c|c|c|}
\hline & $\mathrm{n}$ & $\%$ & OR & (95\% OR) & $p$ value \\
\hline \multicolumn{6}{|l|}{ Sex } \\
\hline Female & $566 / 2140$ & 26.5 & 1.00 & & \\
\hline Male & $501 / 1410$ & 35.6 & 1.53 & $(1.33-1.77)$ & $<0.001$ \\
\hline \multicolumn{6}{|l|}{ Age } \\
\hline 80 years and over & $144 / 453$ & 31.8 & 1.00 & & \\
\hline 60 to 79 years & $463 / 1584$ & 29.2 & 0.89 & $(0.71-1.11)$ & 0.286 \\
\hline 40 to 59 years & $371 / 1242$ & 29.9 & 0.91 & $(0.72-1.15)$ & 0.441 \\
\hline 18 to 39 years & $90 / 271$ & 33.2 & 1.06 & $(0.77-1.47)$ & 0.704 \\
\hline \multicolumn{6}{|l|}{ Country of birth* } \\
\hline Australia & $783 / 2611$ & 30.0 & 1.00 & & \\
\hline UK/Ireland & $138 / 505$ & 27.4 & 0.88 & $(0.71-1.09)$ & 0.239 \\
\hline Other & $142 / 426$ & 33.3 & 1.17 & $(0.94-1.45)$ & 0.166 \\
\hline \multicolumn{6}{|l|}{$\begin{array}{l}\text { Language } \\
\text { spoken at } \\
\text { home* }^{*}\end{array}$} \\
\hline English & $933 / 3160$ & 29.5 & 1.00 & & \\
\hline Other & $130 / 382$ & 34.0 & 1.23 & $(0.98-1.54)$ & 0.069 \\
\hline \multicolumn{6}{|l|}{ Marital status* } \\
\hline $\begin{array}{l}\text { Married/live with } \\
\text { partner }\end{array}$ & $728 / 2459$ & 29.6 & 1.00 & & \\
\hline $\begin{array}{l}\text { Separated/ } \\
\text { Divorced }\end{array}$ & $93 / 336$ & 27.5 & 0.90 & $(0.70-1.17)$ & 0.439 \\
\hline Widowed & $172 / 541$ & 31.8 & 1.11 & $(0.91-1.35)$ & 0.318 \\
\hline Never married & $72 / 210$ & 34.1 & 1.23 & $(0.92-1.66)$ & 0.168 \\
\hline \multicolumn{6}{|l|}{$\begin{array}{l}\text { Area of } \\
\text { residence }\end{array}$} \\
\hline Metropolitan & $758 / 2532$ & 29.9 & 1.00 & & \\
\hline Country & $310 / 1018$ & 30.4 & 1.02 & $(0.87-1.20)$ & 0.769 \\
\hline \multicolumn{6}{|l|}{ Education* } \\
\hline Degree or higher & $108 / 488$ & 22.1 & 1.00 & & \\
\hline $\begin{array}{l}\text { Trade/Certificate/ } \\
\text { Diploma }\end{array}$ & $267 / 832$ & 32.0 & 1.66 & $(1.28-2.15)$ & $<0.001$ \\
\hline $\begin{array}{l}\text { No schooling up } \\
\text { to secondary }\end{array}$ & $690 / 2224$ & 31.0 & 1.59 & $(1.26-2.00)$ & $<0.001$ \\
\hline \multicolumn{6}{|l|}{ Employment* } \\
\hline $\begin{array}{l}\text { Economically } \\
\text { inactive }\end{array}$ & $644 / 2188$ & 29.4 & 1.00 & & \\
\hline Unemployed & $19 / 53$ & 36.3 & 1.36 & $(0.77-2.40)$ & 0.282 \\
\hline Part time & $148 / 495$ & 29.9 & 1.02 & $(0.83-1.27)$ & 0.828 \\
\hline $\begin{array}{l}\text { Full time } \\
\text { employed }\end{array}$ & $256 / 813$ & 31.5 & 1.10 & $(0.93-1.31)$ & 0.274 \\
\hline \multicolumn{6}{|l|}{$\begin{array}{l}\text { Household } \\
\text { income }\end{array}$} \\
\hline Up to $\$ 20,000$ & 230/871 & 26.4 & 1.00 & & \\
\hline$\$ 20,001-\$ 40,000$ & 296/921 & 32.2 & 1.32 & $(1.08-1.62)$ & 0.007 \\
\hline$\$ 40,001-\$ 60,000$ & $126 / 410$ & 30.7 & 1.24 & $(0.96-1.60)$ & 0.107 \\
\hline$\$ 60,001-\$ 80,000$ & $96 / 327$ & 29.2 & 1.15 & $(0.87-1.53)$ & 0.324 \\
\hline $\begin{array}{l}\text { More than } \\
\$ 80,000\end{array}$ & $155 / 533$ & 29.1 & 1.14 & $(0.90-1.45)$ & 0.277 \\
\hline Not stated & $165 / 488$ & 33.8 & 1.42 & $(1.12-1.81)$ & 0.004 \\
\hline \multicolumn{6}{|l|}{ SEIFA* } \\
\hline Highest quintile & $187 / 688$ & 27.2 & 1.00 & & \\
\hline
\end{tabular}

Table 2 Univariate analysis of demographic variables for adults with arthritis but don't know type, South Australia, 2006-8 (Continued)

\begin{tabular}{llllll}
\hline High quintile & $221 / 685$ & 32.3 & 1.28 & $(1.01-1.61)$ & $\mathbf{0 . 0 3 9}$ \\
Middle quintile & $226 / 800$ & 28.2 & 1.05 & $(0.84-1.32)$ & 0.661 \\
Low quintile & $241 / 751$ & 32.0 & 1.26 & $(1.00-1.58)$ & $\mathbf{0 . 0 4 6}$ \\
Lowest quintile & $191 / 620$ & 30.8 & 1.74 & $(0.94-1.51)$ & 0.153 \\
\hline
\end{tabular}

*Not stated category not reported

between medical specialists and the general public, and also between cultures and languages [9]. The condition of $\mathrm{OA}$, in particular, raises some problems as there is no standard definition of OA used in all studies [14]. This is because OA can be clinically, radiographically or symptomatically defined and the prevalence is highly dependent on the definition used [9]. No national arthritis trend information exists that has used the same data source over time, emphasising the unique value of these South Australian surveillance data obtained using a consistent methodology.

There has been little change in the proportion of respondents reporting that they do not know the type of arthritis that they have over time. This may indicate that there have been few education programs related to

Table 3 Multivariate analysis of demographic variables for adults with arthritis but don't know type, South Australia, 2006-8

\begin{tabular}{|c|c|c|c|}
\hline & OR & (95\% OR) & $\overline{p \text { value }}$ \\
\hline \multicolumn{4}{|l|}{ Sex } \\
\hline Female & 1.00 & & \\
\hline Male & 1.65 & $(1.42-1.93)$ & $<0.001$ \\
\hline \multicolumn{4}{|l|}{ Language spoken at home* } \\
\hline English & 1.00 & & \\
\hline Other & 1.28 & $(1.02-1.61)$ & 0.034 \\
\hline \multicolumn{4}{|l|}{ Marital status* } \\
\hline Married/live with partner & 1.00 & & \\
\hline Separated/Divorced & 1.10 & $(0.84-1.44)$ & 0.472 \\
\hline Widowed & 1.49 & $(1.18-1.89)$ & 0.001 \\
\hline Never married & 1.32 & $(0.98-1.80)$ & 0.071 \\
\hline \multicolumn{4}{|l|}{ Education* } \\
\hline Degree or higher & 1.00 & & \\
\hline Trade/Certificate/Diploma & 1.64 & $(1.26-2.14)$ & $<0.001$ \\
\hline No schooling up to secondary & 1.78 & $(1.39-2.28)$ & $<0.001$ \\
\hline \multicolumn{4}{|l|}{ Household income } \\
\hline up to $\$ 20,000$ & 1.00 & & \\
\hline$\$ 20,001-\$ 40,000$ & 1.50 & $(1.20-1.88)$ & $<0.001$ \\
\hline$\$ 40,001-\$ 60,000$ & 1.46 & $(1.11-1.94)$ & 0.008 \\
\hline$\$ 60,001-\$ 80,000$ & 1.36 & $(1.00-1.85)$ & 0.051 \\
\hline More than $\$ 80,000$ & 1.47 & $(1.11-1.94)$ & 0.007 \\
\hline Not stated & 1.60 & $(1.24-2.06)$ & $<0.001$ \\
\hline
\end{tabular}


arthritis or that they have had little impact. Thus there is likely to be little knowledge generally about the condition. Multivariate analysis indicated that variables associated with income, education, cultural diversity and sex were associated with not knowing the type of arthritis. We have not measured health literacy in this study. However, measures used in research are largely to measure the capacity and skills of people in being able to acquire and process information. The question of how well health literacy correlates with disease knowledge is unknown in this case but there is ample evidence elsewhere to indicate lower health literacy is associated with less disease knowledge $[2,4,5,7]$. Clinicians are unable to correctly identify those with limited FHL [26], and using educational level will misclassify a substantial proportion of people as health literate/illiterate [2,3,6,7,27-29]. Our data would strongly suggest explicitly taking into account the level of health literacy of individuals when communicating about arthritis may be critical in establishing understanding, particularly considering the multiple meanings different clinicians and others imply when they use the term "arthritis".

There are limitations to these data that may have had an effect on the observed prevalence of arthritis. First, the methodology of SAMSS requires that participants have a landline telephone number listed in the EWP. South Australians without a landline telephone, or without a landline number listed in the EWP are excluded in the sampling, which may result in an underestimate of arthritis prevalence given that arthritis is associated with increasing age. As many older people who could possibly have arthritis live in institutions without the availability of a personal landline, these estimates are likely to be an underestimation of the true problem. Secondly, although a representative sample of Aboriginal people are obtained in each SAMSS, the small absolute number of Aboriginal people surveyed prevent comparisons of arthritis prevalence trends between indigenous and non-indigenous groups. Third, the study includes only the self-reported prevalence of arthritis, that is, those people with doctor diagnosed arthritis. It has been documented that a higher prevalence is found for musculoskeletal diseases from self-reporting than when estimated from physical examinations $[10,14,30]$ This has raised concerns over the validity of the self-reporting of these conditions and it has been argued that the validity of the self-reporting of musculoskeletal conditions is poor when the figures are compared with physical examination [10]. In addition, Lawrence et al [31] presents concerns over the severe limitations with regard to estimating prevalence of specific conditions (using selfreport data) due to the fact that individuals frequently do not know and therefore cannot identify the specific musculoskeletal disease that affects them. However, it is concluded that self-report data are better used to identify the more generic condition of "arthritis". In order to overcome this problem of definition in establishing the prevalence of arthritis in the population, the consensus of a working group of experts was that "symptomatic arthritis" rather than "radiographic evidence of arthritis" should be used to measure prevalence [31]. Symptomatic includes both self-reported arthritis as well as reported pain in the joints [10]. The data presented in this paper are solely based on self-report and the limitations associated with this data collection (as discussed above) are acknowledged.

\section{Conclusions}

Continued surveillance, using population tools such as the South Australian Monitoring and Surveillance System, will monitor key arthritis indicators. The ultimate aim of collection and analysis of surveillance data is to detect population changes at an early stage, to inform policy and program decisions that initiate action. While this paper focuses on a single condition, health literacy is an important aspect in implementing actions across the spectrum of health care issues. The link from surveillance to public health practice is essential [15], not only if the health outcomes of the population who have arthritis are to be improved, but also if the general population is to be prevented from developing arthritis and the upward trend in arthritis prevalence is to be curtailed.

\section{Author details}

'Population Research \& Outcomes Studies Unit, SA Health, Adelaide, SA, Australia. ${ }^{2}$ Department of Medicine, University of Adelaide, Adelaide, SA Australia. ${ }^{3}$ Rheumatology Unit, The Queen Elizabeth Hospital, Woodville, SA, Australia. ${ }^{4}$ The Health Observatory, The University of Adelaide, The Queen Elizabeth Hospital Campus, Woodville, SA, Australia. ${ }^{5}$ Public Health and Clinical Coordination, SA Health, Adelaide, SA, Australia. ${ }^{6}$ Arthritis Foundation of South Australia, Adelaide, SA, Australia.

\section{Authors' contributions}

Each author has contributed intellectually to this work

TKG statistical analysis, interpretation of data, writing manuscript; CLH, RJA, $D B, J B$ AWT interpretation of data, writing manuscript. All authors read and approved the final manuscript.

\section{Competing interests}

The authors declare that they have no competing interests.

Received: 20 January 2010 Accepted: 6 August 2010

Published: 6 August 2010

\section{References}

1. Australian Institute of Health and Welfare: Australia's Health 2004 Canberra: AlHW 2004.

2. Ad Hoc Committee on Health Literacy for the Council on Scientific Affairs: Health Literacy: Report of the Council of Scientific Affairs. JAMA 1999, 281:552-7.

3. Safeer RS, Keenan J: Health literacy: The gap between physicians and patients. Am Fam Physician 2005, 72:463-468. 
4. Schillinger D, Piette J, Grumbach K, Wang F, Wilson C, Daher C, LeongGrotz K, Castro C, Bindman AB: Closing the loop: physician communication with diabetic patients who have low health literacy. Arch Intern Med 2003, 153:83-90.

5. Williams MV, Baker DW, Parker RM, Nurss JR: Relationship of functional health literacy to patients' knowledge of their chronic disease. A study of patients with hypertension and diabetes. Arch Intern Med 1998, 158:166-172.

6. Davis TC, Arnold C, Berkel HJ, Nandy I, Jackson RH, Glass J: Knowledge and attitude on screening mammography among low-literate, low-income women. Cancer 1996, 78:1912-1920.

7. Williams MV, Baker DW, Honig EG, Lee TM, Nowlan A: Inadequate literacy is a barrier to asthma knowledge and self-care. Chest 1998, 114:1008-1015

8. Kirsch I, Jungeblut A, Jenkins L, Kolstad A: Adult Literacy in America: A First Look at the Findings of the National Adult Literacy Survey Washington, DC: National Center for Education Statistics, U.S. Department of Education 1993 [http://nces.ed.gov/pubs93/93275.pdf].

9. Kaestle CF, Damon-Moore HD, Stedman LC, Tinsely K, Tolinger WV Jr: Literacy in the United States: Readers and Reading Since 1880 New Haven: Yale University Press 1991.

10. Picavet HS, Hazes JM: Prevalence of self reported musculoskeletal diseases is high. Ann Rheum Dis 2003, 62:644-50.

11. Bombard JM, Powell KE, Martin LM, Helmick CG, Wilson WH: Validity and reliability of self-reported arthritis: Georgia Senior Centers, 2000-2001. Am J Prev Med 2005, 28:251-257.

12. Centers for Disease Control and Prevention: State prevalence of selfreported doctor-diagnosed arthritis and arthritis-attributable activity limitation - United States, 2003. MMWR 2006, 55:477-481.

13. Reginster JY: The prevalence and burden of arthritis. Rheumatology 2002, 41(supp 1):3-6.

14. Helmick CG, Felson DT, Lawrence RC, Gabriel S, Hirsch R, Kwoh CK Liang MH, Kremers HM, Mayes MD, Merkel PA, Pillemer SR, Reveille JD, Stone $J H$, for the National Arthritis Data Workgroup: Estimates of the prevalence of arthritis and selected musculoskeletal disorders in the United States. Arthritis Rheum 2008, 58:15-25.

15. Australian Institute of Health and Welfare: Arthritis and Osteoporosis in Australia 2008 Canberra: AlHW 2008.

16. Gill T, Taylor A, Leach G, Parsons J: Arthritis in South Australia - Who has it and What is the Impact? Adelaide: South Australian Department of Health 2003.

17. Australian Health Ministers Conference 2005: A National Action Plan for Osteoarthritis, Rheumatoid Arthritis and Osteoporosis 2004-2006 Canberra: Australian Government Department of Health and Ageing.

18. Population Research and Outcome Studies Unit: The South Australian Monitoring and Surveillance System (SAMSS) Brief Report 2002 - 20 Adelaide: South Australian Department of Health 2002.

19. Population Research and Outcome Studies Unit: SAMSS Survey Questionnaire. South Australian Monitoring and Surveillance System (SAMSS) Technical Paper Series No. 2/04 Adelaide: South Australian Department of Health 2004

20. Australian Bureau of Statistics: Australian Social Trends, 2008 ABS Cat. No. 4102.0. Canberra: Australian Bureau of Statistics 2008.

21. Australian Bureau of Statistics: 2006 Census Community Profile Series: South Australia Canberra: Australian Bureau of Statistics 2008 [http://www.abs.gov. au/websitedbs/D3310114.nsf/home/Census+data].

22. Australian Bureau of Statistics: Census of Population and Housing: SocioEconomic Indexes for Areas (SEIFA). Technical Paper. Australia 2001 ABS Cat. No. 2039.0.55.001. Canberra: Australian Bureau of Statistics 2004.

23. SPSS Inc: SPSS Advanced Statistics 15.0.1 Chicago: SPSS Inc 2007.

24. Hosmer D, Lemeshow S: Applied Logistic Regression New York: John Wiley \& Sons, 22000.

25. Walitt BT, Constantinescu G, Weinstein A, Wang H, Hernandez RK, Hsia J, Howard BV: Validation of self-report of rheumatoid arthritis and systemic lupus erythematosus: The Women's Health Initiative. J Rheumatol 2008, 35:811-818.

26. Kelly PA, Haidet P: Physician overestimation of patient literacy: a potential source of health care disparities. Patient Educ Couns 2007, 66:119-22
27. Nielsen-Bohlman L, Panzer A, Kindig D, (Eds): Committee on Health Literacy. A prescription to end confusion Washington, DC: National Academies Press 2004.

28. Howard DH, Gazmararian JA, Parker RM: The impact of low health literacy on medical costs for Medicare managed care enrollees. Am J Med 2005, 118:371-377.

29. Barber MN, Staples M, Osborne RH, Clerehan R, Elder C, Buchbinder R: Up to a quarter of the Australian population may have suboptimal health literacy depending upon the measurement tool: results from a population-based survey. Health Promot Int 2009, 24:252-261.

30. Heliovaara M, Aromaa A, Klaukka T, Knekt P, Joukemaa M, Impivaara O Reliability and validity of interview data on chronic diseases: the miniFinland health survey. J Clin Epidemiol 1993, 46:181-191.

31. Lawrence RC, Helmick CG, Arnett FC, Deyo RA, Felson DT, Giannini EH, Heyse SP, Hirsch R, Hochberg MC, Hunder GG, Liang MH, Pillemer SR, Steen VD, Wolfe F: Estimates of the prevalence of arthritis and selected musculoskeletal disorders in the United States. Arthritis Rheum 1998, 41:778-799.

\section{Pre-publication history}

The pre-publication history for this paper can be accessed here: http://www.biomedcentral.com/1471-2474/11/174/prepub

doi:10.1186/1471-2474-11-174

Cite this article as: Gill et al: "I know I have arthritis but I don't know what type". Understanding and knowledge of this chronic condition. BMC Musculoskeletal Disorders 2010 11:174.

\section{Submit your next manuscript to BioMed Central and take full advantage of:}

- Convenient online submission

- Thorough peer review

- No space constraints or color figure charges

- Immediate publication on acceptance

- Inclusion in PubMed, CAS, Scopus and Google Scholar

- Research which is freely available for redistribution

Submit your manuscript at www.biomedcentral.com/submit
Ciomed Central 